KA N D A I

\begin{tabular}{|l|l|l|}
\hline Volume 16 & No. 1, Mei 2020 & Halaman 1-12 \\
\hline
\end{tabular}

\title{
IDENTIFIKASI AHOK DAN PESAN SATIRE DALAM CERPEN “KORUPTOR KITA TERCINTA” KARYA AGUS NOOR (Identification of Ahok's Character and Satire Message in The Short Story "Our Beloved Corruptors" by Agus Noor)
}

\author{
Chafit Ulya \\ Universitas Sebelas Maret \\ Jalan Ir. Sutami 36A, Kentingan, Surakarta, Indonesia \\ Pos-el: chafit@staff.uns.ac.id
}

(Diterima: 24 Oktober 2019; Direvisi: 25 Februari 2020; Disetujui: 21 April 2020)

\begin{abstract}
An art work is strongly related to social context, culture, or politic because it reflects the condition of life. For example, in responding corruption problem, Agus Noor in his literary works shows other dimensions such as the reality of corruption and political actors involved inside with the touch of a unique satire humor. The main purpose of this study was to describe and explain (1) the identification of Ahok's character in the short story "Koruptor Kita Tercinta" (KKT) by Agus Noor; (2) the satire message in short story KKT by Agus Noor. The method used in this study was descriptive-qualitative method with the main data source was taken from the short story collection entitled Jokes of The Corruptors. The data were taken by using "recording-noting" technique to be further analyzed using analysisinteractive model. From the study, there were some conclusions: (1) the main character in the short story jokes of the corruptors has a strong identification with Ahok. That identification was based on the act experienced by the main character in the story which was compared with the reality and also through some characteristics described such as assertive, straightforward, to be brave, and to speak frankly. (2) The satire message contained in the short story was used as the media of critic by the author toward the corruption reality in Indonesia. Satire message was used by the author as an alternative way in conveying critics on corruption in a fresh and ironic way.
\end{abstract}

Keywords: Ahok, satire message, corruption reality, our beloved corruptor, Agus Noor

\section{Abstrak}

Lahirnya sebuah karya sastra tidak bisa dilepaskan dari konteks sosial, budaya, ataupun politik yang melingkupinya karena sastra merupakan mimesis kehidupan. Dalam menyikapi persoalan korupsi, Agus Noor dalam karya cerpennya menghadirkan dimensi lain, yakni realitas korupsi dan aktor politik yang ada di dalamnya dengan muatan humor satire yang khas. Yang menjadi tujuan dalam penelitian ini ialah mendeskripsikan dan menjelaskan (1) indentifikasi sosok Ahok dalam cerpen KKT karya Agus Noor; (2) pesan satire dalam cerpen KKT karya Agus Noor. Metode yang digunakan dalam penelitian ini ialah deskriptif-kualitatif dengan pendekatan mimesis sastra. Sumber data berupa buku kumpulan cerpen Lelucon Para Koruptor. Data diambil dengan teknik rekam-catat untuk selanjutnya dianalisis dengan model analisis interaktif. Dari hasil kajian, dihasilkan simpulan bahwa (1) Tokoh utama dalam cerpen KKT memiliki identifikasi yang erat dengan sosok Ahok. Identifikasi tersebut didasarkan pada peristiwa yang dialami tokoh dalam cerita dengan realitas Ahok serta melalui karakter keras, lugas, berani, dan bicara ceplasceplos apa adanya. (2) Pesan satire dalam cerpen digunakan sebagai media kritik oleh pangarang terhadap realitas korupsi yang dilakukan para koruptor. Pesan satire digunakan oleh pangarang sebagai media alternatif dalam menyampaikan kritik tentang korupsi melalui guyonan "asem” yang segar nan miris.

Kata-kata kunci: Ahok, pesan satire, realitas korupsi, koruptor kita tercinta, Agus Noor 
DOI: $10.26499 / j k . v 16 i 1.1797$

How to cite: Ulya, C (2020). Identifikasi Ahok dan pesan satire dalam cerpen "Koruptor Kita Tercinta" karya Agus Noor. Kandai, 16(1), 1-12 (DOI: 10.26499/jk.v16i1.1797)

\section{PENDAHULUAN}

Lahirnya sebuah karya sastra tidak bisa dilepaskan dari konteks sosial, budaya, atau politik yang melingkupinya karena karya sastra merupakan tiruan kehidupan manusia. Dalam dunia sastra, hal ini dikenal dengan istilah mimesis. Teori mimesis merupakan pendekatan dalam studi karya sastra yang paling kuno dan sederhana. Pendekatan ini dicetuskan oleh Plato yang kemudian ditentang oleh muridnya sendiri, Aristoteles (Abrams, 1976).

Meskipun ditentang oleh Aristoteles, pendekatan mimesis ini sampai sekarang masih menjadi salah satu pendekatan kritik yang diakui dalam dunia sastra. Bahkan, keberadaan pendekatan mimesis diperkuat oleh pendapat dari para pakar sastra era 8090-an. Teeuw menyatakan bahwa kehidupan nyata ini tidak saja dapat dikaitkan dengan dunia sastra, tetapi juga masalah lain, di antaranya filsafat, psikologi, sosiologi, dan sebagainya (Teeuw, 1984). Secara lebih lugas, Wellek \& Warren berpendapat bahwa sifat sastra memang sebagian besar menyajikan kehidupan dunia nyata, yaitu keadaan sosial masyarakat (Wellek \& Warren, 1989). Dengan demikian, tidak dapat dimungkiri bahwa objek dan topik dalam sastra tidak bisa dilepaskan dari kehidupan nyata meskipun itu bukan satu-satunya.

Dalam melihat karya cerpen "Koruptor Kita Tercinta" karya Agus Noor, pendekatan mimesis dapat dijadikan pijakan utama dalam memahami unsur dan makna di dalamnya. Dengan melandaskan pada pendekatan mimesis, kita akan bisa melihat keterkaitan antara karya Agus
Noor ini dan realitas sosial-politik yang ada. Maka, kasus korupsi dan aktor politik Indonesia tidak bisa dilepaskan dari kajian ini. Dalam hal ini, sosok Ahok atau Basuki Tjahaya Purnama, mantan Gubernur DKI Jakarta diyakini merupakan mimesis atas tokoh-tokoh utama dalam cerpen.

Ada sejumlah kemiripan, baik peristiwa yang dialami maupun ciri-ciri fisik dan psikis, antara sosok Ahok dengan tokoh utama. Kemiripan tersebut selanjutnya dijadikan bahan untuk menangkap pesan-pesan satire yang terkandung di dalam cerpen. Berangkat dari pemikiran inilah dilakukan analisis secara mendalam terkait cerpen "Koruptor Kita Tercinta" (selanjutnya disebut KKT) karya Agus Noor ini, dengan tujuan mendekripsikan dan menjelaskan: (1) indentifikasi sosok Ahok dalam cerpen KKT karya Agus Noor; (2) pesan satire dalam cerpen KKT karya Agus Noor.

\section{LANDASAN TEORI}

Sampai saat ini, korupsi masih menjadi persoalan serius yang belum teratasi di Indonesia. Deretan catatan buruk tentang korupsi terpampang jelas di berbagai media. Ada ratusan kasus dengan ratusan koruptor setiap tahun. Belum lagi miliaran, bahkan triliunan rupiah uang negara yang ditilap oleh para oknum pejabat negara dan swasta. Kita bisa melansir catatan tersebut berdasarkan temuan ICW berikut. Pada tahun 2018, ICW mencatat sebanyak 454 kasus korupsi yang ditangani oleh penegak hukum, baik kejaksaan, kepolisian, maupun KPK. Dari kasuskasus tersebut, sebanyak 1.087 orang dari berbagai latar belakang profesi 
ditetapkan sebagai tersangka. Kerugian negara yang diakibatkan oleh tindak korupsi tersebut sebesar Rp5,6 triliun, uang suap sebesar Rp134,7 miliar, uang pungutan liar sebesar Rp6,7 miliar, dan pencucian uang sebesar Rp91 miliar (Alamsyah, Abid, \& Sunaryanto, 2018).

Tentu saja semua orang merasa kecewa, kesal, dan marah mengetahui situasi tersebut. Cara mengekspresikan perasaan tersebut tentu berbeda satu dengan yang lainnya. Ada yang mengungkapkannya melalui jalur hukum dengan melaporkan berbagai penyelewengan anggaran. Ada yang menempuh jalur birokrasi dengan memperketat sistem pengawasan dan tata kelola keuangan negara. Ada yang memilih jalur pendidikan dengan edukasi dan internalisasi nilai-nilai antikorupsi kepada peserta didik, seperti halnya pernah dilakukan dalam materi ajar apresiasi puisi (Ulya \& Wardani, 2017). Namun, ada pula yang mengekspresikannya melalui jalan prosa sastra.

Jalur terakhir inilah yang dipilih oleh Agus Noor. Melalui kumpulan cerpen Lelucon Para Koruptor, Agus Noor mencoba menertawakan berbagai kasus korupsi yang terjadi di negeri ini menjadi guyonan "asem" nan satire. Di dalam pandangan Agus Noor, korupsi bisa dijadikan objek untuk ditertawakan, tetapi tentu saja muatan kritiknya tetap tersampaikan.

Dalam banyak karya cerpennya, Agus Noor sering melandaskan ceritanya kepada realitas sosial-politik yang terjadi di Indonesia. Penelitian yang berjudul "Menyibak Relevansi Permasalahan Sosial dalam Kumpulan Cerita Pendek Karya Agus Noor dengan Kenyataan Sosial" menemukan adanya keterkaitan antara permasalahan yang diangkat penulis dengan kenyataan sosial yang terjadi saat ini (Mauliddin, Nuryatin, \& Mulyani, 2017). Dengan demikian, dapat dinyatakan bahwa cerpen-cerpen Agus Noor dilandasi dengan realitas sosial yang terjadi di masyarakat.

Kritik sosial Agus Noor tidak saja dilakukan pada masa-masa sekarang, tetapi juga pada masa Orde Baru. Akan tetapi, ada perbedaan formula kritik yang dilakukannya pada dua periode tersebut. Pada masa Orde Baru, kritik Agus Noor disampaikan secara simbolik. Dalam cerpen "BH", Agus Noor secara simbolik mengkritik pembatasanpembatasan yang dilakukan penguasa terhadap orang-orang lemah yang berada di bawah kekuasaan Orde Baru Ia menggunakan perempuan sebagai perwakilan dari kelompok masyarakat umumnya yang sedang memperjuangkan hak-hak mereka (Woodrich, 2013).

Sementara itu, pada masa reformasi, kritik Agus Noor disampaikan secara lebih terbuka. Hal ini sebagaimana ditemukan dalam penelitian Utami, Wendra, dan Yasa yang berjudul "Representasi Hukum dalam Cerpen Hakim Sarmin Karya Agus Noor: Analisis Konflik Sosial Lewis A. Coser". Secara jelas, Agus Noor mengkritik ketidakadilan hukum yang merupakan representasi dan refleksi dari peristiwaperistiwa hukum yang terjadi di Indonesia. Pada masa ini, Agus Noor tidak lagi menggunakan simbol-simbol untuk mengkritik penguasa (Utami, Wendra, \& Yasa, 2019).

Pada perkembangan selanjutnya, kritik atas persoalan sosial-politik yang disampaikan Agus Noor dalam cerpencerpennya dilakukan dengan nada humor satire, sebagaimana banyak ditemukan dalam kumpulan cerpen Lelucon Para Koruptor. Satire politik (political satire) yang dipilih oleh Agus Noor dalam karyanyaialah salah satu bagian satire yang secara khusus mengambil sisi hiburan dari sebuah fenomena politik (Freedman, 2009). 
Satire merupakan gaya bahasa yang digunakan untuk menyatakan sindiran atau ejekan terhadap suatu keadaan, atau bisa juga seseorang. Pesan satire dapat diwujudkan dalam berbagai bentuk, antara lain karikatur, tulisan, karya seni, ataupun karya sastra (Freedman, 2009).

Satire secara historis digunakan untuk tujuan mendiskreditkan penguasa (Plevriti, 2014). Dengan demikian, sudah menjadi hal yang wajar apabila pesanpesan satire sering ditujukan untuk "menyerang" seseorang atau institusi pemerintah atau penguasa. Menyerang di sini dimaknai secara simbolik untuk tujuan membuka ruang interpretasi bagi siapa pun yang membaca atau menyaksikan pesan tersebut (Freedman, 2009). Pesan satire biasanya dikemas dalam bentuk humor agar pesan tersebut tidak saja menyerang pihak-pihak yang ingin diserang, tetapi juga sekaligus mampu memberikan hiburan bagi pihak lainnya.

"Satiric narrative works indirectly through parodic alteration of celebratory forms, established discourses, and dogmatic pronouncements" (Palmeri, 1990). Pesan satire banyak digunakan untuk segala sesuatu yang bersifat humoris sekaligus mengandung hal-hal yang bersifat konyol, khususnya berkaitan dengan kekuasaan. Ada tiga karakterisitik satire, yaitu kritik, ironi, dan hal tersirat (Palmeri, 1990). Pesan satire selalu berangkat dari kritik atas perilaku buruk manusia yang ditujukan untuk mendorong terjadinya perubahan sosial. Pesan satire juga disampaikan dengan menggunakan ironi yang dibumbui dengan humor. Selain itu, pesan satire tidak disampaikan secara terbuka tetapi menggunakan simbol-simbol kritis.

\section{METODE PENELITIAN}

Penelitian ini menggunakan pendekatan mimesis yang dikembangkan dengan teori sosiologi sastra. Metode yang digunakan dalam penelitian ini adalah metode deskriptif kualitatif dengan mendasarkan pada proses penarikan simpulan berdasarkan analisis data yang ditemukan serta berpegangan pada teori yang ada (Sutopo, 2006).

Sumber data penelitian diambil dari buku kumpulan cerpen Lelucon Para Koruptor (2017) yang ditulis oleh Agus Noor. Dari 12 cerpen yang ada, dipilihlah cerpen "Koruptor Kita Tercinta" sebagai objek kajian penelitian. Pemilihan cerpen tersebut didasarkan pada topik kajian dan tujuan yang diharapkan dari penelitian, yakni upaya mendapatkan data berupa katakata yang menggambarkan pendekatan mimetik.

Teknik pengumpulan data dilakukan dengan menggunakan teknik baca-catat. Selanjutnya, data yang terkumpul dianalisis dengan menggunakan model analisis interaktif yang tersusun atas reduksi data, penyajian data, dan penarikan simpulan/verifikasi (Miles \& Huberman, 1994).

\section{PEMBAHASAN}

\section{Identifikasi Ahok dalam Cerpen "Koruptor Kita Tercnta"}

Cerpen KKT merupakan cerpen ketiga dari kumpulan cerpen Lelucon Para Koruptor yang ditulis oleh Agus Noor. Cerpen ini mengisahkan potret seorang koruptor yang sangat dicintai dan dikagumi oleh masyarakat karena keberaniannya di dalam mengemukakan persoalan korupsi secara jujur dan terang-terangan. Selain karena keberaniannya tersebut, hal yang 
membuat tokoh koruptor ini sangat dicintai adalah keberhasilannya dalam menjadikannya sosok pejabat yang bersih. Akan tetapi, pada akhirnya ia tersangkut oleh sebuah kasus korupsi yang dalam ukuran normal sangat tidak wajar, yaitu tersangkut proyek pembangunan toilet umum.

Kekaguman publik terhadap sosok pejabat bersih ini runtuh seketika. Kekecewaan ini diluapkan dengan cacian dan makian yang dilemparkan kepadanya. Namun, sang koruptor ini justru membalas cacian dan makian ini dengan sikap ksatria, pemberani, dan jujur sehingga publik pun lantas menjadikannya tokoh idola. Oleh publik, sang koruptor ini menjelma menjadi sosok yang sangat dicintai. Sebaliknya, bagi para pejabat lainnya, ia dianggap sebagai ancaman karena terlalu berani membocorkan aneka motif, trend, bahkan filosofi korupsi yang dilakukan para pejabat.

Berangkat dari pokok gagasan inilah muncul dugaan bahwa sosok koruptor tercinta pada cerpen KKT ini identik dengan sosok Ahok, mantan Gubernur DKI Jakarta. Namun demikian, karya sastra tetap harus disadari sebagai karya mimetis sekaligus imajinatif. Dengan demikian, potret Ahok tidak dilukiskan dalam kerangka deskriptif-eksplanatif, tetapi naratifimajinatif. Ada sejumlah kemiripan yang dapat dirujuk pada realitas sosial yang terjadi. Namun, ada juga perbedaannya.

Secara gagasan, cerpen KKT jelas tidak memiliki keterkaitan langsung dengan sosok Ahok. Ahok tidak pernah tersangkut kasus korupsi yang menyeretnya ke penjara. Ia pernah masuk penjara karena kasus penistaan agama, bukan korupsi. Dengan demikian, pandangan koruptor yang disematkan kepada sosok Ahok menjadi kontradiktif. Inilah justru yang menjadikan cerpen ini menarik. Realitas sosial yang ditampilkan jelas berbeda dengan realitas fiksi di dalam cerpen.

Ada banyak penanda yang bisa digunakan untuk mengidentifikasi sosok Ahok sebagai sang koruptor tercinta dalam cerpen ini. Pada bagian awal, pengarang sudah membuka dengan mengenalkan sosok sang koruptor tercinta tersebut.

"Oleh majalah terpenting di negeri ini, ia dinobatkan menjadi Man of the Year sebagai pejabat paling jujur. Karena kejujurannya itulah, ia dihormati dan dicintai" (Noor, 2017).

Pada waktu masih menjabat sebagai Wakil Gubernur DKI, Ahok pernah mendapatkan penghargaan dari Bung Hatta Award Anti-Corruption Award tahun 2013. Oleh majalah Tempo, Ahok juga pernah masuk 10 tokoh yang mengubah Indonesia pada tahun 2006. Setahun kemudian, Ahok kembali mendapatkan penghargaan sebagai Tokoh Antikorupsi oleh Kamar Dagang Indonesia, Kementerian Pendayagunaan Aparatur Negara, dan Masyarakat Transparansi Indonesia (Tempo, 2013).

Pengalaman ber-stand up comedy yang dilakukan Ahok dalam berbagai kesempatan juga disinggung dalam cerpen KKT ini.

"Sebagai mantan daripada koruptor yang baik, pertama-tama izinkanlah daripada saya mengucapken daripada puja dan puji syukur kepada Tuhan Yang Maha Esa, karena telah memberiken daripada rahmat dan hidayah-Nya, sehingga sampai hari ini masih banyak daripada kolegakolega saya yang bisa dengan tenang terus melaksanaken daripada korupsinya secara baik dan tenang. Semoga dilempangkan jalannya, dan diterima di sisi Tuhan," begitu ia membuka penampilannya di acara stand up comedy, yang langsung 
disambut tawa dan tepuk tangan riuh (Noor, 2017).

Dalam berbagai kesempatan, Ahok memang tampak piawai bermain stand up comedy. Seperti saat mereka tampil dalam acara talk show Rosi berikut.

\begin{abstract}
"Aku ada cerita, ini pas Lebaran kemarin, ngunjungi kampung, ngunjungi temen bapak saya yang sudah tua. Katanya, Hok kamu tahu nggak, di hutan, kalau kita sama bapakmu pergi potong kayu, pasti dipesenin cari yang paling lurus, untuk dipotong," kata Ahok.

"Jadi kamu nggak usah heran, banyak yang ingin motong kalian berdua (Ahok-Djarot) karena kalian ini terlalu lurus di dunia politik," Ahok menambahkan.
\end{abstract}

Hadirin tertawa. (Suara, 2016)

Bahkan, Ahok pernah mengungkapkan keinginannya untuk terjun menjadi komika ketika sudah tak lagi menjabat Gubernur DKI, sebagaimana dikutip dari Kompas berikut.

Terancam Dipecat, Ahok Siap Geluti "Stand Up Comedy" (Aziza, 2015).

Kesamaan yang lain ditampilkan dalam keinginan Ahok memiliki sebuah acara televisi dengan tajuk "Ahok Show" yang pada akhirnya tidak dapat terealisasi. Dalam cerpen KKT, keinginan tersebut juga dimunculkan pengarang sebagai berikut.

Popularitasnya yang makin meroket membuat ia ditawari untuk memandu acara televisi yang diberi judul Corruptor Got Talent. Ia telah menjadi orang yang paling dicintai di negeri ini. (Noor, 2017).

Buku biografi Ahok juga menjadi penanda identitasnya sebagai tokoh utama dalam cerpen. Dalam KKT, sang
Koruptor Tercinta juga menerbitkan biografi hidupnya yang disusun melalui wawancara eksklusif dengan dirinya, kawan-kawannya, guru-gurunya, tetangga, dan banyak lagi, sebagaimana tampak pada kutipan berikut.

Proses penulisan biografi lumayan lancar. Ia menjawab dengan antusias dan terbuka apa pun yang ingin saya ketahui. Sejarah hidupnya tak ia tutup-tutupi, sehingga saya selalu menemukan kejutan-kejutan yang tak terduga yang merangsang saya untuk terus menggali apa yang selama ini tak banyak diketahui tentangnya ....

Saya menemui kawan-kawannya semasa sekolah dasar, mantan gurugurunya, tetangga, dan siapa pun yang saya anggap perlu untuk saya gali informasinya (Noor, 2017).

Kembali kepada realitas tentang Ahok, kisah hidupnya pun diangkat ke dalam beberapa buku biografi. Salah satu buku biografi tentang Ahok yang paling terkenal berjudul $A H O K$ : Wawancara Eksklusif dengan Ahok, Keluarga, Sahabat, dan Warga ditulis oleh Meicky Shoreamanis Panggabean.

Pada bagian terakhir cerpen, pengarang menutup kisah sang koruptor tercinta ini dengan mengatakan bahwa di kota kelahiran sang koruptor tersebut, akan dibangun monumen untuk menghormati jasa-jasanya.

Kabarnya, di kota kelahirannya, orang-orang sudah menyiapkan monumen berupa patung untuk menghormatinya (Noor, 2017).

Hal yang sama juga ditemukan pada realitasnya, yakni melalui pembangunan tempat wisata Kampoeng Ahok. Tempat wisata itu dibangun oleh keluarga Ahok agar menjadi semacam ensiklopedi masa lalu kehidupan Ahok.

Selain penggalan-penggalan yang menggambarkan puzzling peristiwa yang 
identik dengan sosok Ahok, karakter yang digambarkan oleh pengarang juga memiliki kemiripan dengan Ahok. Sebagaimana diketahui, Ahok memiliki sifat berani dan suka bicara ceplasceplos. Sifat ini juga yang tampak pada tokoh koruptor tercinta. Kita bisa melihat hal itu dari keberaniannya dalam mengungkapkan berbagai kegilaan koruptor melalui tuturan yang disampaikan sang tokoh.

..... Kamu lihat sendiri, sekarang banyak koruptor yang kabur melarikan diri ke luar negeri. Koruptor macam apa itu? Nggak pantes koruptor jadi buronan. Biarlah yang jadi buronan itu hanya para penjahat atau orang mesum. Koruptor sejati tak boleh lari dari tanggung jawabnya. Harus tangguh menghadapi risiko-risiko hukum sepahit apa pun. Jangan malah pura-pura sakit, begitu dipanggil ke pangadilan. Itu namanya mental kere!" (Noor, 2017).

Gaya bicara yang lugas, apa adanya, bahkan tidak jarang pula kasar dan sarkastis yang dimiliki oleh Ahok inilah yang dijadikan modal oleh pengarang untuk mengkritik persoalan korupsi di Indonesia. Meskipun tidak secara kasar (menggunakan gaya bahasa sarkasme), pengarang sangat jeli mengutarakan gagasan kritisnya terhadap persoalan korupsi. Dengan begitu lincah dan leluasa, pengarang memasukkan kritik-kritik pedasnya dalam balutan guyonan segar nan miris melalui dialog yang sebagian besar keluar dari mulut sang tokoh. Oleh karenanya, tak mengherankan apabila pesan satire dalam cerpen KKT ini begitu terasa. Melalui identifikasi Ahok, pengarang memiliki keleluasaan di dalam menyampaikan pesan satire dalam cerpen, sebagaimana disajikan pada pembahasan di bawah ini.
Pesan Satire dalam Cerpen "Koruptor Kita Tercinta"

Cerpen KKT ini mengisahkan pengakuan jujur dan apa adanya seorang koruptor atas berbagai persoalan korupsi, baik yang dilakukannya sendiri maupun orang lain. Sosok koruptor yang ada dalam cerpen ini memiliki kemiripan dengan sosok mantan Gubernur DKI, Ahok. Dalam cerpen ini, sosok Ahok diperkenalkan sebagai koruptor yang sangat dicintai karena keberaniannya mengungkapkan secara terbuka dan apa adanya tentang sekelumit persoalan korupsi di negeri ini. Banyak gagasan brilian yang muncul dari pemikirannya, baik ketika masih menjabat gubernur maupun setelah ditetapkan sebagai terpidana. Salah satu gagasan brilian tersebut adalah program pembangunan toilet umum di wilayahnya.

.... Lagipula, pembangunan toilet umum itu memang diperlukan agar negara bisa mengontrol setiap kali para warga buang hajat, karena ini menyangkut pendapatan negara dari sektor pajak buang hajat. (Noor, 2017).

Pembangunan toilet umum dalam konteks di atas tentu hanya lelucon belaka. Mana ada pemerintah sampai mengurusi persoalan buang hajat warganya. Di sinilah letak satire dalam cerpen ini. Pengarang sengaja memunculkan toilet sebagai simbol ruang privasi setiap orang untuk menyalurkan berbagai hasrat, keinginan, dan juga pemikiran. Penggalan agar negara bisa mengontrol setiap kali para warga buang hajat memiliki makna tersirat, bukan sekadar buang hajat berkaitan dengan metabolisme tubuh, melainkan buang hajat yang bersifat menyalurkan pendapat atau aspirasi. Munculnya undang-undang ITE bisa 
dipandang sebagai upaya negara mengontrol aspirasi dan kritik warganya.

Selain itu, proyek pembangunan toilet umum yang lantas menyeret Sang Koruptor Tercinta ke penjara ini juga mengingatkan kasus penistaan agama yang dilakukan oleh Ahok. Toilet secara simbolis merupakan tempat untuk mengeluarkan kotoran. Kotoran tersebut bisa berupa unek-unek yang selama ini dipendam. Ahok, dalam hal ini, tersangkut kasus penistaan agama juga dalam kerangka mencoba mengungkapkan unek-uneknya terkait dengan pelabelan "pemimpin kafir" dalam kampanye politik yang diikutinya.

Kritik yang disampaikan dengan sebuah lelucon memang memberikan impresi yang berbeda. Ia tidak lagi bersuara keras, tetapi tetap mampu menusuk secara dalam. Inilah satire tersebut. Pesan satire dalam cerpen KKT ini juga ditampilkan melalui pengakuan tulus seorang koruptor. Di hadapan para wartawan, sang koruptor tercinta ini justru secara sukarela menyematkan gelar koruptor dalam dirinya, sebagaimana tampak pada penggalan berikut.

Para wartawan yang semula saling celetuk mengajukan pertanyaan, langsung menyimak baik-baik. "Dengan tulus setulus-tulusnya, juga dengan segala kerendahan hati, saya mengakui, saya ini memang koruptor." Ia kembali tersenyum, lalu bicara dengan bahasa lebih halus, "Inggih, leres, dalem punika koruptor. Iya, benar, saya ini koruptor. Koruptor lahir batin." (Noor, 2017).

Sekali lagi, penggalan di atas sangatlah satire. Hal yang sangat tidak mungkin dalam tradisi perkorupsian bangsa ini, seorang yang sudah dinyatakan tersangka atau terdakwa bahkan terpidana dalam kasus korupsi mengakui bahwa benar dia melakukan korupsi. Yang ada justru sebaliknya. Mereka justru membela diri dengan alasan dijebak, menjadi korban, atau malah menyalahkan pihak lain. Sikap ksatria inilah yang tidak ada pada diri koruptor di Indonesia. Oleh karenanya, dalam sejarah perkorupsian bangsa ini, rasanya belum pernah ada cerita seorang koruptor mengakui bahwa dirinya melakukan kesalahan dan meminta maaf kepada seluruh bangsa Indonesia atas kesalahannya.

Seloroh di bawah ini mempertegas karakter para koruptor. Kalimat "Korupsi itu buruk! Yang baik ya kalau tidak ketahuan" merupakan guyon satire. Korupsi itu boleh-boleh saja selama tidak ketahuan. Dan kalau sudah ketahuan, orang tidak menyesalinya sebagai sebuah kesalahan, melainkan menyesal karena ketahuan. Prinsip inilah yang tampaknya dipegang oleh para koruptor. Ketika disajikan dalam cerpen ini, kita seolah ditelanjangi bahwa selama ini kita sudah melewatkan dagelan politik yang begitu menggelikan.

.... Saya akan berjuang bersama-sama kalian, seluruh rakyat, untuk bahu membahu memberantas korupsi. Jangan sampai kalian ikut-ikutan korupsi. Korupsi itu buruk! Yang baik ya kalau tidak ketahuan." (Noor, 2017).

Dalam pandangan sang Koruptor Tercinta, koruptor itu aset negara yang harus dikelola dengan baik dan benar. Kalimat ini sungguh terasa "asem" (umpatan Jawa). Mengapa terasa "asem"? Karena ketika tidak dikelola dengan baik, negara ini bisa lumpuh karena semua pejabat dan aparat negara masuk penjara. Ini adalah sindiran tajam bahwa korupsi merupakan hal yang tidak bisa dilepaskan dari praktik birokrasi di negara ini. Bahkan, kita semua pun mengetahui dan menyadari hal tersebut. 
Jadi, ketika masyarakat Indonesia mendengar berita tertangkapnya seorang koruptor, mereka sebenarnya hanya berpura-pura kaget dan dalam hati mereka berkata, "Korupsi boleh-boleh saja, tetapi yang wajar. Berhentilah korupsi sebelum kenyang."

Ia setuju pemberantasan korupsi, tetapi juga mengingatkan bahwa koruptor itu aset negara yang harus dikelola dengan baik dan bijak. "Kalau tidak," katanya, "negara ini akan lumpuh karena semua aparat dan pejabatnya masuk penjara. Bayangkan, apa jadinya kalau semua sipir penjara pun masuk penjara? Siapa yang akan menjaga penjara?" Ia tertawa. "Korupsi ndak papa, asal tak berlebihan. Ibaratnya, berhentilah korupsi sebelum kenyang." (Noor, 2017).

Korupsi yang sudah masuk ke semua lini dan dilakukan terangterangan pun tak luput dari sorotan untuk dikritisi. Tentu saja, kesan satire sangat terasa.

"Kamu pasti pernah mendengar lelucon, dulu koruptor melakukan korupsi di bawah meja. Kemudian mulai terang-terangan, korupsi dilakukan di atas meja. Sekarang, mejanya pun sudah berani dikorupsi. Ini benar-benar menyedihkan saya. Para koruptor itu sama sekali tak memahami kalau sesungguhnya korupsi itu sebuah seni. Perlu imajinasi seperti seorang seniman menghasilkan karya yang memesona. Korupsi itu seni tingkat tinggi. ... (Noor, 2017).

Penggalan di atas menyuratkan pesan bahwa koruptor sudah tidak tahu malu dalam menjalankan praktik-praktik korupsinya. Bidang-bidang yang seharusnya bebas dari perkorupsian pun sudah tidak bisa dijamin kebersihannya.
Bisa dilihat, dana kesehatan sudah dikorupsi, dana pendidikan dikorupsi, dana haji pun dikorupsi, bahkan dana pemberantasan korupsi pun ikut-ikutan dikorupsi.

Sindiran dalam bentuk guyonan ringan menjadi salah satu cara yang dilakukan pengarang untuk mengkritik perilaku koruptor. Hal ini diungkapkan melalui cerita berikut.

"Suatu hari ada seekor babi dan seorang koruptor bertemu harimau yang lapar. Mereka tak bisa melarikan diri. Salah satu harus dimakan harimau itu. Siapa yang selamat?"

"Babi. Sebab harimau itu tak mau makan babi, sebab haram."

"Salah!" katanya. "Yang selamat koruptor itu. Sebab ia berhasil menyuap harimau agar memakan babi, meskipun haram. Hahahaha...." Ia terbahak, meledek cara berpikir saya yang dianggapnya masih linear. (Noor, 2017).

Penggalan cerita di atas merupakan sindiran terhadap koruptor yang mampu menyuap siapa pun selama ia mempunyai uang atau kekuasaan. Bagi koruptor, cerita di atas semestinya menjadi cambukan keras. Kritik-kritik dalam balutan komedi sejenis itu pun sebenarnya sering dilakukan. Bahkan, dalam suatu kesempatan, ada seorang anak SMK yang secara terbuka melakukan stand up comedy di depan para anggota DPR RI. Anak SMK tersebut secara terbuka dan berani menyindir perilaku anggota dewan yang tidak berbeda dengan anak SMK yang suka bolos, tidur di kelas, menilap uang SPP, dan sebagainya.

"Demokrasi itu kan dari rakyat, oleh rakyat, untuk rakyat. Harus atas nama rakyat. Makanya, korupsi yang baik itu ya mesti mengatasnamakan rakyat. 
Semangatnya adalah kerakyatan. Melakukan korupsi untuk menyelamatkan uang rakyat agar aman di kantong kita. ..." (Noor, 2017).

Penggalan di atas merupakan puncak kesatiran dalam cerpen KKT, yakni ketika rakyat hanya diatasnamakan untuk berbagai kepentingan politik sekelompok orang atau golongan. Yang paling "asem" dari penggalan di atas adalah kalimat terakhir bahwa korupsi dilakukan untuk menyelamatkan uang rakyat agar aman di kantong kita, sebelum dikorupsi oleh yang lainnya.

Pesan satire menjadi salah satu terobosan baru manakala kritik-kritik konvensional mengalami kebuntuan. Demonstrasi mahasiswa yang menentang pengesahan RUU KUHP beberapa waktu lalu menjadi contoh bahwa aktivitas kritik terbuka di ruang publik sudah dianggap tidak relevan lagi. Komedi-satire dianggap memiliki jangkauan yang lebih luas dalam merespons peristiwa politik melalui sarana-sarana dan cara-cara yang tidak terduga (Wadipalapa, 2015). Oleh karenanya, kebuntuan respons konvensional melalui demonstrasi yang mulai kehilangan perhatian publik dapat dijawab oleh media-media berbasis humor, baik guyonan satire, stand up comedy, meme politik, dan sebagainya.

Kebuntuan kritik melalui media konvensional juga membuka ruang kritik baru bagi generasi milenial. Dewasa ini, ada media-media baru yang menampung gagasan kritis kaum milenial ini, tetapi dengan gaya komunikasi ala anak muda. Sebut saja Mojok.co, Tirto.id, Kompasiana, dan sebagainya. Kajian yang pernah dilakukan Utomo pada media mojok.co menyimpulkan bahwa mojok.co yang dikelola oleh para penulis muda menunjukkan bahwa generasi milenial yang selama ini dianggap apolitis mampu merespons isu-isu sosial dan politik dengan gaya komunikasi khas anak muda yang cair, humoris, dan penuh pesan satire (Utomo, 2015).

Sindiran halus tetapi menohok dan satire saat ini menjadi pilihan terbaik untuk menyampaikan kritik. Sindiran halus dan satire berbeda dengan ujaran kebencian (hate speech). Ada ruangruang kreativitas yang menjadikan satire dapat diterima, sedangkan sarkasme tidak. Pilihan satire tersebut membuka peluang terbukanya ruang-ruang kritik yang lebih luas, seperti meme, karikatur, ataupun karya sastra. Pada ranah karikatur, dengan memanfaatkan sarana kebahasaan yang ada, karikatur dapat dijadikan media dalam menyampaikan kritik (Resticka, 2017).

Melalui pesan-pesan satire dalam cerpen KKT sebagaimana sudah dijelaskan di atas, dapat kita ambil pelajaran betapa urat saraf malu koruptor kita sudah putus. Sindiran-sindiran yang dikemukakan dalam cerpen ini begitu keras terasa. Sebagai karya mimetis, sindiran keras tersebut tidak mungkin diungkapkan tanpa realitas sosial yang terjadi di sekitar kita. Maka, pesan terakhir untuk para koruptor dapat diambil dari lirik lagu "Ilir7" yang beberapa waktu lalu juga dipakai sebagai salah satu materi demo mahasiswa. "Setan apa yang merasukimu. Hingga kau tega menghianatiku. Yang tulus memilihmu".

\section{PENUTUP}

Dari hasil analisis dan pembahasan yang sudah dikemukakan di depan, dapat ditarik simpulan sebagai berikut. (1) Tokoh utama dalam cerpen KKT memiliki identifikasi yang erat dengan sosok Ahok. Identifikasi tersebut didasarkan pada peristiwa yang dialami tokoh dalam cerita dengan realitas Ahok yang terekam melalui media-media. Selain itu, identifikasi Ahok juga 
ditemukan melalui karakter tokoh utama yang bersifat keras, lugas, berani, dan bicara ceplas-ceplos apa adanya. (2) Pesan satire dalam cerpen digunakan sebagai media kritik oleh pangarang terhadap realitas korupsi yang dilakukan para koruptor. Pesan satire tentang korupsi tersebut disampaikan melalui tokoh utama yang memiliki karakter pemberani serta suka bicara ceplas ceplos dan apa adanya. Pesan satire digunakan oleh pangarang sebagai media alternatif dalam menyampaikan kritik tentang korupsi melalui guyonan "asem" yang segar nan miris.

\section{DAFTAR PUSTAKA}

Abrams, M. H. (1976). The Mirror and Lamp: Romantic Theory an the Critical Tradition (Oxford Uni). Oxford.

Alamsyah, W., Abid, L., \& Sunaryanto, A. (2018). Laporan Tren Penindakan Korupsi Tahun 2018. Jakarta.

Aziza, K. S. (2015, April 6). Terancam Dipecat, Ahok Siap Geluti Stand Up Comedy. Kompas.Com. Retrieved from https://tekno.kompas.com/read/2 015/04/06/16465991/Terancam.D ipecat.Ahok.Siapkan.Diri.Geluti. Stand.Up.Comedy

Freedman, L. (2009). The Offensive Art: Political Satire and Its Censorship Around The World from Beerbohm to Borat. In Choice Reviews Online. https://doi.org/10.5860/choice.47 $-1489$
Mauliddin, M. Y., Nuryatin, A., \& Mulyani, M. (2017). Menyibak Relevansi Permasalahan Sosial dalam Kumpulan Cerita Pendek Karya Agus Noor dengan Kenyataan Sosial. JP-BSI (Jurnal Pendidikan Bahasa Dan Sastra Indonesia), 2(2), 49-52. https://doi.org/10.26737/jpbsi.v2i2.243

Miles, M., \& Huberman, A. (1994). Miles and Huberman Chapter 2. In Qualitative Data Analysis.

Noor, A. (2017). Lelucon Para Koruptor. Yogyakarta: Diva Press.

Palmeri, F. (1990). Satire in Narrative. Austin: University of Texas Press.

Plevriti, V. (2014). Satirical User Generated Memes as an Effective Source of Political Criticism, Extending Debate and Enhancing Civic Engangement. Warwick University.

Resticka, G. A. (2017). Pemanfaatan Aspek Kebahasaan Bentuk Kata Tuturan Humor dalam Karikatur. Haluan Sastra Budaya, 1(1), 4160.

https://doi.org/10.20961/hsb.v1i1 .4296

Suara. (2016, December 16). Begini Gaya Ahok dan Djarot Stand Up Comedy di Acara Debat. Suara.Com. Retrieved from https://www.suara.com/news/201 6/12/16/110100/begini-gayaahok-dan-djarot-stand-upcomedy-di-acara-debat 
Sutopo, H. B. (2006). Metode Penelitian Kualitatif. Surakarta: UNS Press.

Teeuw, A. (1984). Sastra dan Ilmu Sastra. Jakarta: Dunia Pustaka Jaya.

Tempo. (2013, October 16). Alasan Bung Hatta Award Beri Penghargaan pada Ahok. Retrieved from https://metro.tempo.co/read/5221 72/alasan-bung-hatta-award-beripenghargaan-padaahok/full\&view $=$ ok

Ulya, C., \& Wardani, N. E. (2017). Model Internalisasi Pendidikan Antikorupsi dalam Mata Kuliah Kajian dan Apresiasi Puisi. Konferensi Nasional Bahasa Dan Sastra IV, 121-125. Surakarta: Program Doktor Pendidikan Bahasa Indonesia FKIP UNS.

Utami, M. T., Wendra, I. W., \& Yasa, I. N. (2019). Representasi Hukum Dalam Cerpen Hakim Sarmin Karya Agus Noor: Analisis Konflik Sosial Lewis A. Coser. Jurnal Pendidikan Bahasa Dan Sastra Indonesia Undiksha, 9(2), 227-239.

https://doi.org/10.23887/jjpbs.v9i 2.20428
Utomo, W. P. (2015). Menertawakan Politik: Anak Muda, Satire, dan Parodi dalam Situs Mojok.co. Jurnal Studi Pemuda, 4(1), 195205.

Wadipalapa, R. P. (2015). Meme Culture \& Komedi-Satire Politik: Kontestasi Pemilihan Presiden dalam Media Baru. Jurnal Ilmu Komunikasi, 12(1), 1-18. https://doi.org/10.24002/jik.v12i1 .440

Wellek, R., \& Warren, A. (1989). Theory of Literature. Jakarta: PT Gramedia.

Woodrich, C. (2013). Perempuan dan Negara: Kajian Feminis dalam Konteks Sosial "BH" Karya Agus Noor. Jurnal Kawistara, 3(2), 117-226. https://doi.org/10.22146/kawistar a.3981 